\title{
Identification of an Operon, Pil-Chp, That Controls Twitching Motility and Virulence in Xylella fastidiosa
}

\author{
Luciana Cursino, ${ }^{1,2}$ Cheryl D. Galvani, ${ }^{1,2}$ Dusit Athinuwat, ${ }^{1}$ Paulo A. Zaini, ${ }^{1,3}$ Yaxin Li, ${ }^{1}$ \\ Leonardo De La Fuente, ${ }^{1,4}$ Harvey C. Hoch, ${ }^{1}$ Thomas J. Burr, ${ }^{1}$ and Patricia Mowery ${ }^{2}$ \\ ${ }^{1}$ Department of Plant Pathology and Plant-Microbe Biology, Cornell University-New York State Agricultural Experiment Station, \\ Geneva, NY 14456, U.S.A.; ${ }^{2}$ Department of Biology, Hobart and William Smith Colleges, Geneva, NY 14456, U.S.A.; \\ ${ }^{3}$ Department of Biochemistry, University of São Paulo, SP 05508-000, Brazil; ${ }^{4}$ Department of Entomology and Plant \\ Pathology, Auburn University, Auburn, AL 36849, U.S.A.
}

Submitted 28 October 2010. Accepted 10 June 2011.

\begin{abstract}
Xylella fastidiosa is an important phytopathogenic bacterium that causes many serious plant diseases, including Pierce's disease of grapevines. Disease manifestation by $X$. fastidiosa is associated with the expression of several factors, including the type IV pili that are required for twitching motility. We provide evidence that an operon, named Pil-Chp, with genes homologous to those found in chemotaxis systems, regulates twitching motility. Transposon insertion into the pill gene of the operon resulted in loss of twitching motility (pilL is homologous to cheA genes encoding kinases). The $X$. fastidiosa mutant maintained the type IV pili, indicating that the disrupted pilL or downstream operon genes are involved in pili function, and not biogenesis. The mutated $X$. fastidiosa produced less biofilm than wild-type cells, indicating that the operon contributes to biofilm formation. Finally, in planta the mutant produced delayed and less severe disease, indicating that the Pil-Chp operon contributes to the virulence of $X$. fastidiosa, presumably through its role in twitching motility.
\end{abstract}

Xylella fastidiosa is a nonflagellated, xylem-limited gramnegative bacterium transmitted to plants by xylem sap-feeding insects (Almeida et al. 2005). It causes diseases of many economically important crops such as Pierce's disease (PD) in grape and citrus variegated chlorosis in sweet orange (Purcell and Hopkins 1996). Movement within the grapevine xylem sap is proposed to be important for the development of $X$. fastidiosainduced PD (Chatterjee et al. 2008a). X. fastidiosa moves via twitching motility (Meng et al. 2005). Twitching is a flagellumindependent means of bacterial motility that affects host colonization and functions by the extension, attachment, and then retraction of polar type IV pili (Mattick 2002).

The ability of $X$. fastidiosa to move against the transpiration stream in grape xylem vessels is associated with type IV pilimediated twitching motility (Meng et al. 2005). Several genes associated with pili biogenesis in X. fastidiosa have been identified as required for twitching and virulence (Cursino et al. 2009; Li et al. 2007; Meng et al. 2005). In addition, genes associated with multiple regulatory networks involved in twitching motility, biofilm formation, and virulence have been identified (da Silva et al. 2008; Shi et al. 2007; Shi et al. 2009). For example, the pilR/pilS gene pair that belongs to the family of two-component regulatory systems has been described in many bacterial species

Corresponding author: P. Mowery; E-mail: mowery@hws.edu; Telephone: +1.315 .781 .3184 ; Fax: +1.315.781.3860.
(Winther-Larsen and Koomey 2002). PilS is a predicted sensory protein that, when stimulated by the appropriate environmental signals, activates PilR through kinase activity. PilR then regulates transcription of pilA, which encodes the major pilin protein of the type IV pilus. We previously reported that an X. fastidiosa pilR mutant lacks type IV pili and does not exhibit twitchingmediated motility (Li et al. 2007).

Microbial motility can be controlled by chemotaxis, a process in which microbes sense stimuli in their environment and move toward or away from a chemical. The gram-negative model system for chemotaxis, Escherichia coli, expresses transmembrane chemoreceptors that associate with histidine kinases (CheA) via coupling proteins (CheW) (Hazelbauer et al. 2008). Ligand binding to the chemoreceptor alters the phosphorylation state of the CheA kinase, which transfers the phosphate group to the response regulator protein $\mathrm{CheY}$ that, in turn, interacts with the flagella motor proteins. E. coli chemoreceptors adapt to ligand concentrations through reversible methylation changes regulated by the methyltransferase, CheR, and methylesterase, CheB. Examination of other bacteria shows variation of such factors as the number of chemotaxis systems, what chemotaxis protein components are added to or subtracted from the systems, and the functions regulated by the chemotaxis genes (Alexander and Zhulin 2007; Hamer et al. 2010; Kirby 2009).

Chemosensory systems are known to regulate motility by the type IV pili. For instance, Myxococcus xanthus, which performs adventurous (A) motility and type IV pilus-mediated social (S) motility, has eight chemotaxis operons, of which three (Che4, Dif, and Frz,) are involved in type IV pili responses (Zusman et al. 2007). Additionally, Pseudomonas aeruginosa bacteria with both pili and flagella have five chemosensing clusters (Ferandez et al. 2002). The P. aeruginosa chemotaxis cluster IV (Pil-Chp) alters cAMP levels proposed to regulate type IV pili biogenesis or response (Fulcher et al. 2010). In this study, we identified an operon in X. fastidiosa, named PilChp, with genomic similarities to the $P$. aeruginosa CheIV cluster, and examined the association of the X. fastidiosa PilChp operon with twitching motility. The discovery of the chemosensory operon and its effects on twitching, biofilm, and virulence phenotypes are described.

\section{RESULTS}

Identifying twitching minus $X$. fastidiosa mutants.

In order to explore the regulation of $X$. fastidiosa Temecula motility, we performed random transposon mutagenesis and screened for motility minus mutants. Screening involved ex- 
amining colony fringe development, because smooth colony margins are consistent with the loss of twitching function (Meng et al. 2005). Subsequent sequencing of colonies incapable of forming a fringe revealed insertions in the middle of open reading frame XP0874 or pilL, a gene with homology to the chemotaxis histidine kinase, cheA. The mutant was named pil $L_{l}$. We then created a site-directed mutation in the pilL gene via allelic exchange, named pilL $L_{2}$, which was confirmed by polymerase chain reaction (PCR). Like the pilL $L_{1}$ mutant, pilL also resulted from an insertion in the middle of the pilL gene and produced the same nonmotile phenotype as pilL $L_{l}$ (Fig. 1). Because the pill $L_{2}$ is a targeted mutation, as opposed to the random insertion in pil $_{l}$, all results discussed herein are with the pilL $L_{2}$ mutant.

We confirmed that the pil $L_{2}$ mutant was nonmotile in microfluidic chambers (De La Fuente et al. 2007a). Time-lapse video microscopy of cell movement revealed that wild-type
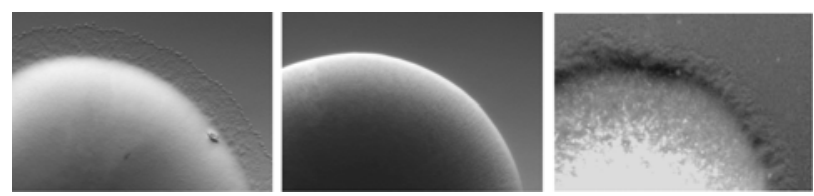

Fig. 1. Representative picture of colony fringe phenotype of the wild-type Xylella fastidiosa (left), a pil $L_{2}$ mutant (middle), and a complemented pilL $L_{2}$ mutant (right) grown on cellophane overlaid on PW agar (Davis et al. 1981). cells moved at an average speed of $0.86 \pm 0.04 \mu \mathrm{m} / \mathrm{min}$ while the pilL $L_{2}$ mutant was not motile $(0 \pm 0 \mu \mathrm{m} / \mathrm{min})$. Together the fringe and chamber results indicate that the chemotaxis system is involved in twitching motility of $X$. fastidiosa.

\section{The $X$. fastidiosa chemosensory system is organized as an operon.}

Chemotaxis genes are often found organized into operons (Hamer et al. 2010). Analyzing the X. fastidiosa Temecula genome surrounding the pilL gene, we found five additional genes homologous to chemotaxis genes (Fig. 2A; Table 1). The farthest upstream gene is pilG, which is predicted to encode a response regulator CheY protein. Downstream of pilG is pill, a putative CheW coupling protein. Next, pilJ is a predicted transmembrane chemoreceptor followed by pilL, predicted to encode a CheA kinase. Downstream of pilL is $\operatorname{chpB}$, a putative methylesterase $\mathrm{CheB}$, and $\operatorname{chpC}$, a second predicted $\mathrm{CheW}$ protein. Overall, the gene organization of the putative $X$. fastidiosa chemotaxis system has parallels to the $P$. aeruginosa CheIV cluster, which is involved in type IV twitching motility (Fig. 2A) (Whitchurch et al. 2004). X. fastidiosa and $P$. aeruginosa differ in that $X$. fastidiosa lacks the $P$. aeruginosa pilH and pilK genes that encode a third CheY and a CheR protein, respectively.

The transcriptional orientation of the $X$. fastidiosa pilG$\operatorname{chpC}$ genes and their close proximity to each other suggest that these genes are co-transcribed with transcription terminat-

\section{A X. fastidiosa chromosome}

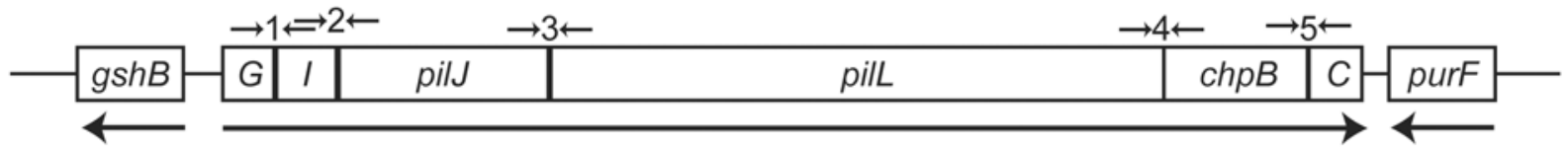

\section{P. aeruginosa chromosome}
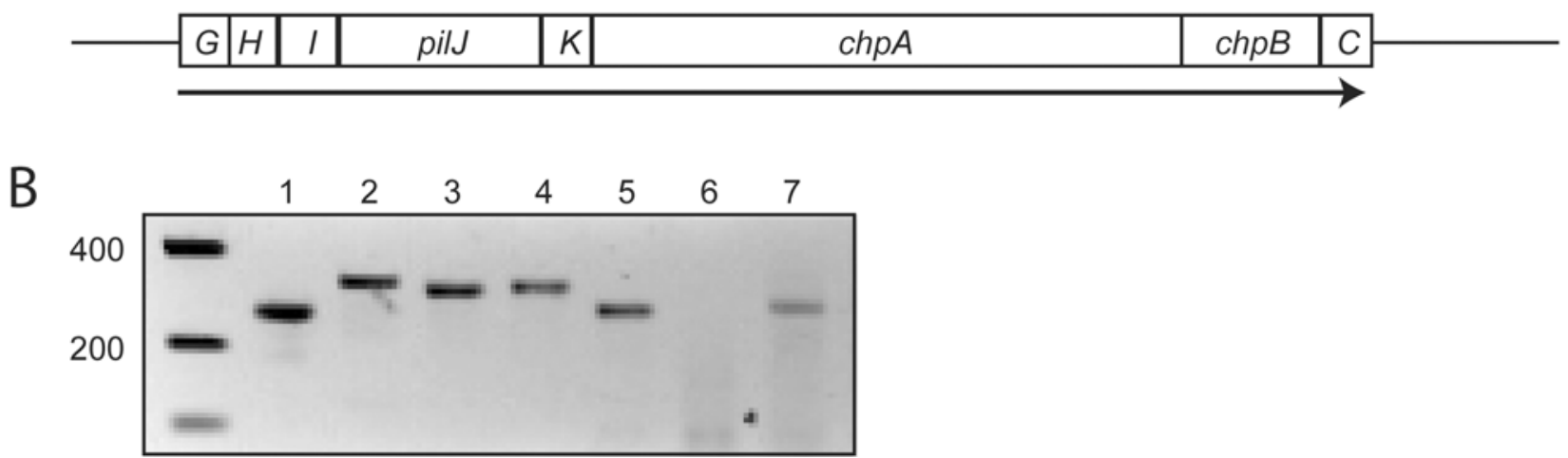

Fig. 2. A, Organization of the predicted Xylella fastidiosa Pil-Chp chemosensory operon and the Pseudomonas aeruginosa CheIV cluster operon. Arrows below the genes represent the direction of transcription. B, Reverse-transcription polymerase chain reaction (RT-PCR) of the Pil-Chp cluster. Total RNA treated with DNAse was used to amplify fragments indicated by the black arrows above the $X$. fastidios $a$ genes. RT-PCR results for primer pairs 1 to 5 . Lane 6 is pilG-pilI without reverse transcriptase but with DNA polymerase. Lane 7 is pilG-pilI fragment amplified from genomic DNA.

Table 1. Predicted components of the Xylella fastidiosa chemosensory operon

\begin{tabular}{|c|c|c|c|c|c|c|}
\hline Gene ID ${ }^{\mathbf{a}}$ & $\begin{array}{c}\text { Predicted } \\
\text { protein }\end{array}$ & $\begin{array}{c}\text { Escherichia coli } \\
\text { homolog }\end{array}$ & $\begin{array}{c}\text { Open reading frame } \\
\text { size (bp) }\end{array}$ & $\begin{array}{c}\text { Protein size } \\
\text { (amino acids) }\end{array}$ & $\begin{array}{c}\text { Molecular weight } \\
\text { (kDa) }\end{array}$ & $\begin{array}{c}\text { Identity to CheIV } \\
(\%)^{\mathbf{b}}\end{array}$ \\
\hline XP0871 & PilG & CheY & 417 & 138 & 15 & 83 \\
\hline XP0872 & PilI & CheW & 531 & 176 & 19 & 34 \\
\hline XP0873 & PilJ & MCP & 2,043 & 680 & 73 & 47 \\
\hline XP0874 & PilL & CheA & 5,178 & 1,725 & 190 & 49 \\
\hline XP0875 & ChpB & CheB & 1,170 & 389 & 41 & 23 \\
\hline XP0876 & ChpC & CheW & 471 & 156 & 17 & 30 \\
\hline
\end{tabular}

\footnotetext{
${ }^{\text {a }}$ Based on SABIA $X$. fastidiosa genome project.
}

${ }^{\mathrm{b}}$ CheIV Pseudomonas aeruginosa cluster homologous proteins. 
ing after $\operatorname{chpC}$. To investigate this organization, reverse-transcription (RT)-PCR tests were performed with oligo primer pairs that spanned the intergenic regions of pilG-pilI, pilI-pilJ,

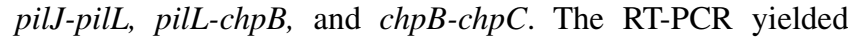
products from approximately 250 to 300 base pairs (Fig. 2B). The first primer pair (pilG-pill) produced products of equal size from both RT-PCR and $X$. fastidiosa genomic DNA. These data indicate that the genes for the putative chemotaxis system in $X$. fastidiosa are organized into an operon, which has been named Pil-Chp. Additionally, given that pilL is in an operon, the transposon insertion in pil $L_{2}$ presumably is a polar mutation resulting in no production of PilL, ChpB, and ChpC proteins. Therefore, we complemented the pil $L_{2}$ mutant using a plasmid containing the pilL, $\operatorname{chpB}$, and $\operatorname{chpC}$ genes and observed restored motility (Fig. 1).

\section{Sequence analysis}

of the $X$. fastidiosa pilL, $\operatorname{chpB}$, and $\operatorname{chpC}$ genes.

Sequence analysis of the pilL gene revealed homology to the E. coli chemotaxis kinase gene, cheA. The pilL gene is predicted to contain the four conserved domain categories of CheA proteins, designated P1, P3, P4, and P5 (Fig. 3A) (Wuichet et al. 2007). PilL has three predicted P1 histidine phosphotransfer domains in its $\mathrm{N}$ terminus. PilL is also predicted to contain a $\mathrm{P} 3$ dimerization domain, as CheA proteins are known to exist as homodimers. Additionally, PilL is predicted to have a P4 ATPase domain (HAPT or HATPase c) that transphosphorylates the P1 domain of the paired CheA monomer. Finally, PilL is predicted to have a P5 CheA regulatory domain (CheW). P5 domains mediate CheA interactions with the chemotaxis protein $\mathrm{CheW}$, which couples CheA with the chemoreceptor. PilL contains an additional CheY-homologous response regulator receiver (REC) domain at the $\mathrm{C}$ terminus. The REC domain contains an Asp1651 residue that corresponds to the highly conserved E. coli CheY Asp57 phosphoaccepting residue for signal transduction (Sanders et al. 1989), suggesting that the pilL gene encodes a functional CheY domain (Fig. 3B). It is noted that pilL is the only cheA ortholog present in the $X$. fastidiosa Temecula genome.

The $X$. fastidios $a \operatorname{ch} p B$ is predicted to encode a chemotaxis methylesterase and the $\operatorname{chp} C$ is predicted to encode a CheW coupling protein. These genes occupy the same relative position in the operon as in the $P$. aeruginosa CheIV cluster; however, they have little sequence identity with the $P$. aeruginosa homologous genes (Table 1). Interestingly, sequence alignment reveals that the $X$. fastidiosa $\operatorname{chpB}$ gene product lacks the conserved serine, histidine, and asparatate sites of a functional CheB serine hydrolase (Fig. 3C) (Krueger et al. 1992; West et al. 1995), suggesting that ChpB may not be functional. No other $c h e B$ orthologs, with or without the expected active site residues, are found in the $X$. fastidiosa Temecula genome. Consistent with other known cheW genes, the $X$. fastidiosa $\operatorname{chp} C$ gene contains a single, unique cheW domain. The $\operatorname{chp} C$ gene is one of two putative $\operatorname{che} W$ genes in the $X$. fastidiosa Pil-Chp operon, as pill is also predicted to encode a CheW.

\section{The pilL, $\operatorname{chpB}$, and $\operatorname{chpC}$ genes do not alter growth or pili formation.}

The fact that the pilL $L_{2}$ mutant does not exhibit twitching motility could be due to a number of factors such as the role of pilL, $\operatorname{chpB}$, or $\operatorname{chpC}$ in cell growth or pili biogenesis. To examine cell growth, wild-type $X$. fastidiosa, pil $L_{2}$, and the complemented strain were grown in PD2 medium (Davis et al. 1981) and spectrometry readings were taken daily. The growth curves of the pil $L_{2}$ mutant and complemented strain paralleled wild-type cells, indicating that loss of pilL and the downstream genes $\operatorname{chp} B$ and $\operatorname{chp} C$ do not affect cell growth (data not shown).

$X$. fastidiosa is a nonflagellated bacterium expressing type I and type IV pili (Li et al. 2007). In P. aeruginosa, the CheIV cluster regulates the formation and extension or retraction of

\section{A X.fastidiosa pill}

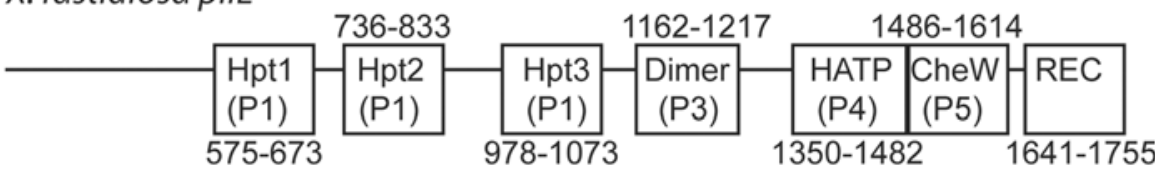

B Xf pilL...TQ SQMP L VMWDDSLTMRKVTSRVLERHNF S - VSVARDG I EALE LLEER IPDLML LD I EMPRMDG 1659 + WDD TMR++ +L+ $+\mathrm{F}+\mathrm{V}$ A DG++AL L+ + D MP MDG Ec cheY...MA DKE LKF LWDDFSTMRR I VRNLLKELGF NNVEEAEDGVDALNKLQAGGYGFVI SDWNMPNMDG 65

$$
\begin{aligned}
& \text { Xf pilL...YE L V AAMRADDRFKS I P I LMI TSRSGDKHR RRAF E IGVQRYLGKPYQEFDL - - -MKN VYDLLGV } \\
& \mathrm{EL}+\text { +RAD ++ }+\mathrm{RM}+\mathrm{T}++++\mathrm{A}+\mathrm{G} \quad \mathrm{Y}+\mathrm{KP}+\mathrm{L}+\text { + ++ } \mathrm{LG}+ \\
& \text { Ec cheY...LE L LKT I RADGAMSAL PVLMVTAEAKKENI QAAAQAGASGYWKPFTAATLEEKLNK I FEKLGM }
\end{aligned}
$$$$
\text { Xf chpB...LA|G| GGP DAI RRLLAAL PAGFKHPVL I KMDGLDGGQY INL VROMGRVTLPVDLAE SG HRI SGAS } 282
$$

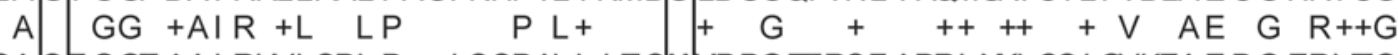$$
\text { Ec cheB...GAST GGT AAI RHVLQPL P - - LSSPAL L I TQHMPPGFTRSF ADRLNKLCQI GVKEAEDG ERVTGMG } 224
$$

Fig. 3. A, Predicted domains of PilL:Hpt (P1 domain/phosphotransfer domains), Dimer (P3 domain/dimerization domain), HATP (P4 domain/HAPTase c/ATP binding site), CheW (P5 domain/CheW binding domain), and response regulator receiver (REC). Numbers indicate the base pair location of the domains. B, Sequence alignment of Xylella fastidiosa PilL REC domain and Escherichia coli CheY. Conserved phospho-accepting residue boxed and in bold. C, Sequence alignment of $X$. fastidiosa $\mathrm{ChpB}$ and $E$. coli $\mathrm{CheB}$ enzymatic region with active site amino acids boxes and in bold. 
type IV pili (Darzins 1993, 1994; DeLange et al. 2007). Given the parallels between the $X$. fastidiosa Pil-Chp operon and the $P$. aeruginosa CheIV cluster, we investigated whether the $X$. fastidiosa pilL $L_{2}$ mutant failed to twitch due to aberrant pili formation. Electron microscopy revealed that the pilL $L_{2}$ mutant possessed the normal complement of both types of pili, mirroring wild-type cells (Fig. 4). These findings indicate that the $X$. fastidiosa pilL, $\operatorname{chpB}$, and $\operatorname{chpC}$ genes are not involved in the biogenesis of pili.

\section{The Pil-Chp operon contributes to biofilm formation.}

Motility and biofilm formation have been shown to have an inverse relationship in X. fastidiosa (Chatterjee et al. 2008b). Therefore, we asked how the transposon insertion into the pilL gene affected biofilm production. We analyzed biofilm formation by wild-type cells, pilL $L_{2}$, and the complemented strain in PD2 medium in Erlenmeyer flasks and quantified biofilm formation by the crystal violet method (Fig. 5). The complemented strain showed nearly wild-type levels of biofilm. However, the pilL $L_{2}$ mutant formed only $24 \%$ of the biofilm of wildtype $X$. fastidiosa levels, revealing that there is a relationship between the Pil-Chp operon and the ability of X. fastidiosa to form biofilm.

The Pil-Chp operon contributes to the development of PD.

To assess pathogenicity of the pil $L_{2}$ mutant, we inoculated grapevines with wild-type and pil $L_{2}$ mutant cells and measured disease development. Significant differences in PD severity were found in the grapevines inoculated with the pil $L_{2}$ mutant compared with wild-type $X$. fastidiosa (Fig. 6). Grapevines inoculated with the pilL $L_{2}$ mutant exhibited delayed symptoms; diseased leaves appeared 4 weeks later than in plants inoculated with wild-type cells. Additionally, compared with wildtype, the pilL $L_{2}$ mutant induced less severe disease than the wild-type strain. After 20 weeks, vines infected with wild-type cells were dead whereas those infected with the pil $L_{2}$ mutant strain had symptoms comparable with an 8- to 12-week infection by wild-type cells. These results indicate that the Pil-Chp operon plays a role in the virulence of $X$. fastidiosa, presumably due to its involvement in twitching motility.

\section{DISCUSSION}

The $X$. fastidiosa Temecula genome is unusual in the fact that it has only one putative chemotaxis operon and chemoreceptor. Many bacteria, such as $P$. aeruginosa, have multiple

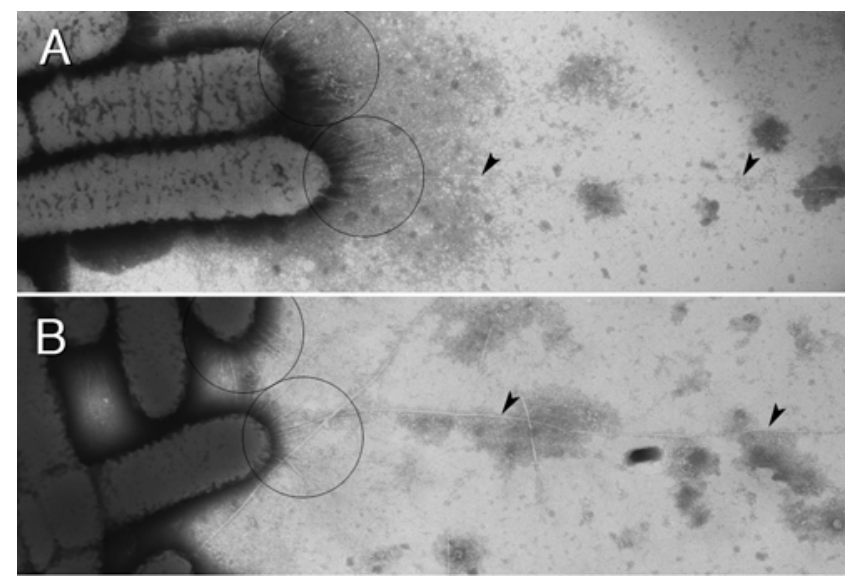

Fig. 4. Representative transmission electron micrographs of phosphotungstic acid negatively stained $\mathbf{A}$, wild-type Xylella fastidiosa cells and $\mathbf{B}$, pilL $L_{2}$ mutant. Arrowheads denote type IV pili. Circled regions denote presence of shorter type I pili. chemotaxis operons regulating diverse functions (Kirby 2009). Bacteria have been identified that have chemosensory proteins implicated in motility, pili formation, transcriptional regulation, and exopolysaccharide production (Kirby 2009). Other bacteria, such as $E$. coli, have only one chemotaxis system but multiple chemoreceptors that respond to an array of signals (Hazelbauer et al. 2008). The presence of a single putative
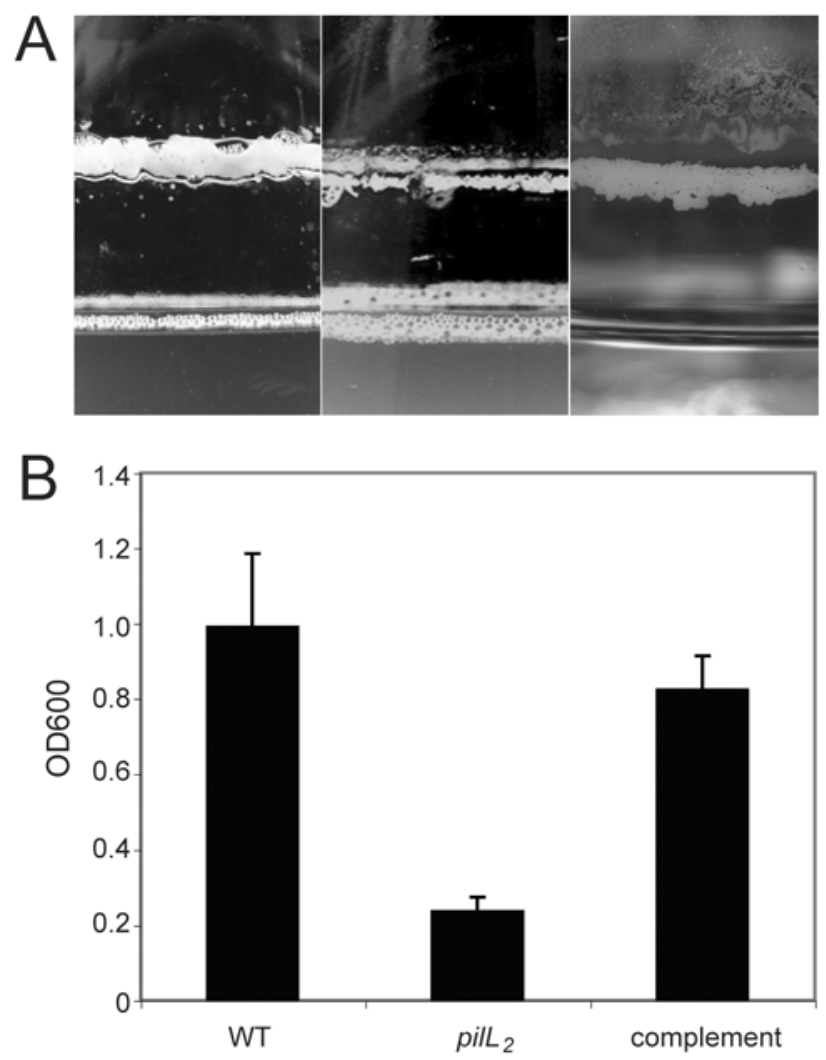

Fig. 5. A, Biofilm formation by wild-type (left), pilL $L_{2}$ mutant (middle), and complemented pilL $L_{2}$ mutant (right) Xylella fastidiosa cells grown in culture flasks following 10 days of growth with agitation. B, Quantitation of biofilm formation by crystal violet. Experiments were repeated five times. Error bars represent the standard deviation of means.

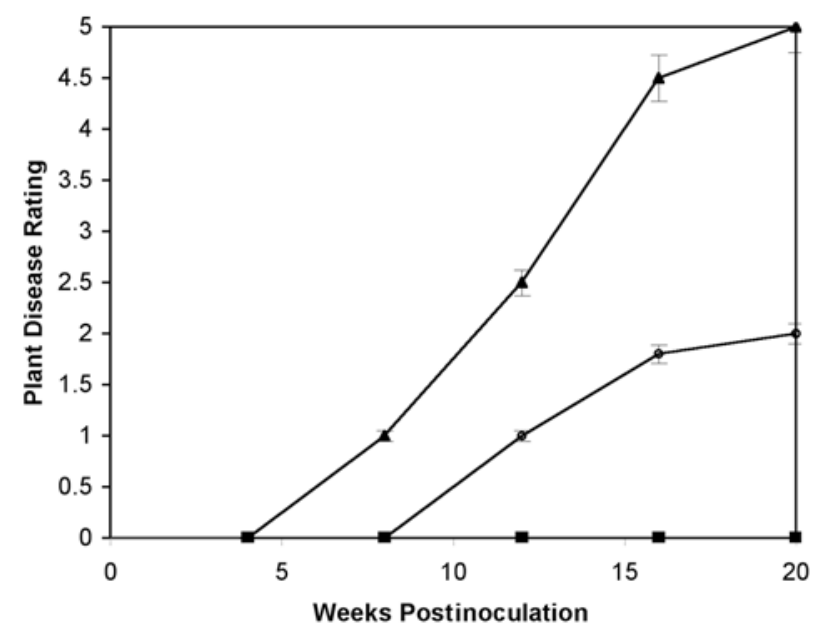

Fig. 6. Pierce's disease assessment of Vitis vinifera L. 'Cabernet Sauvignon' vines inoculated with wild-type (triangle), pilL $L_{2}$ mutant (circle), or buffer control (square) and assessed over 20 weeks. Plant rating on a scale of 0 to 5. Results represent 10 plants per treatment. Error bars in graph indicate standard deviation values; standard deviation values are small where bars are not seen. 
chemotaxis system in $X$. fastidiosa Temecula does not necessarily indicate that there is a single stimulus; chemoreceptors are known to bind multiple chemicals (Falke and Hazelbauer 2001; Hazelbauer et al. 2008). However, a single predicted chemosensory system in $X$. fastidiosa may have evolved due to the organism's highly specific environmental niche within plant xylem vessels, where it is likely to encounter relatively few chemical and environmental signals compared with bacteria living in less environmentally challenging niches. Whether the Pil-Chp operon plays a role when $X$. fastidiosa is in the insect vector needs to be ascertained.

The predicted $X$. fastidiosa PilL protein differs structurally from the canonical E. coli $\mathrm{CheA}$, because the E. coli CheA has only one $\mathrm{P} 1$ domain (histidine-containing phosphotransfer) and no REC domain. However, across bacterial species, CheA proteins are multidomain, highly variable kinases (Wuichet et al. 2007). The $X$. fastidiosa PilL more closely mirrors the $P$. aeruginosa ChpA because both have multiple P1 domains (PilL has three predicted P1 domains whereas ChpA has six) (Whitchurch et al. 2004), and both are predicted to belong to the category of hybrid CheA proteins with the additional C-terminal CheY REC domain; CheY proteins act as a phosphate transporter within chemotaxis systems. As with the $X$. fastidiosa Pil-Chp operon, hybrid cheA genes can exist in operons with separate cheY genes (Bhaya et al. 2001; Whitchurch et al. 2004; Zusman et al. 2007), suggesting that the CheY portion of a hybrid CheA or the additional Che $\mathrm{Y}$ may provide alternative functions. Additionally, like other hybrid CheA proteins, including the $P$. aeruginos ChpA, the $X$. fastidiosa PilL protein lacks the $\mathrm{P} 2$ domain to bind $\mathrm{CheY}$ and CheB (Wuichet et al. 2007). A number of structural differences are predicted between the putative $X$. fastidiosa PilL and $P$. aeruginosa ChpA. Unlike the $P$. aeruginosa ChpA, none of the $X$. fastidiosa-predicted PilL P1 domains contain threonine or serine in the expected histidine phosphorylation site, and the $X$. fastidiosa-predicted PilL lacks a FimL-like domain with homology to FimL, a protein critical for twitching motility (Whitchurch et al. 2004). Consequently, functional differences may be found between the $P$. aeruginosa ChpA and the $X$. fastidios $a$ PilL.

Although involved in numerous processes, hybrid CheA proteins are known to play roles in motility and pili biogenesis. (Bhaya et al. 2001; Whitchurch et al. 2004; Zusman et al. 2007). The $P$. aeruginosa ChpA protein regulates pili formation, extension, and retraction (Whitchurch et al. 2004), as do the three TaxAY proteins of Synechocystis PCC6803 that regulate motility and pili formation (Bhaya et al. 2001). We found that the $X$. fastidiosa pilL gene protein product does not appear to be involved in pili biogenesis. The X. fastidiosa Pil-Chp operon protein products do play a role in twitching motility; however, whether these responses are due to pilL or the downstream genes $\operatorname{chpB}$ and $\operatorname{chpC}$ needs to be examined.

The role, if any, of the $X$. fastidiosa ChpB protein is unknown. Unlike the $P$. aeruginosa CheIV cluster $\operatorname{chpB}$ gene (Whitchurch et al. 2004), the $X$. fastidiosa pilL $L_{2}$ mutation, which presumably lacks ChpB production, does not alter pili levels. Although the $X$. fastidiosa $\operatorname{chpB}$ protein product may have a function unrelated to pili biogenesis, it may not encode a functional protein. Sequence analysis suggests that the $X$. fastidiosa $\operatorname{chp} B$ gene product lacks the expected amino acids for enzymatic activity. Additionally, unlike the $P$. aeruginosa CheIV cluster (Whitchurch et al. 2004), the X. fastidiosa genome has no cheB counterpart gene, cheR; CheB and CheR proteins are known to add and remove methyl groups from chemoreceptors for ligand adaptation (Hazelbauer et al. 2008). Further studies are needed to determine whether or not the $X$. fastidiosa $\operatorname{ch} p B$ has methylesterase function through a novel enzymatic site or functions in a role unrelated to ligand adaptation.

CheW proteins link the chemoreceptors to the kinase CheA (Hazelbauer et al. 2008). The X. fastidiosa chpC, a cheW homolog, does not alter pili levels, in contrast to what is found with the $P$. aeruginosa CheIV cluster protein product $\mathrm{ChpC}$ (Whitchurch et al. 2004). The $X$. fastidiosa $\operatorname{chpC}$ gene is one of two genes in the Pil-Chp operon predicted to encode for a CheW protein, because pill encodes a putative CheW protein. The $P$. aeruginosa CheIV cluster also has the two cheW genes, $\operatorname{chpC}$ and pill, but they provide little insight because it is unknown whether the $P$. aeruginosa $\mathrm{ChpC}$ and Pill have unique or complementary roles (Darzins 1994; Whitchurch et al. 2004). Therefore, further studies are necessary to determine whether the $X$. fastidiosa ChpC is functional and, if so, what role it plays in the chemotaxis system in relation to the putative Pill.

Our results indicate that the $X$. fastidiosa Pil-Chp operon has a positive effect on biofilm formation, because the pil $L_{2}$ mutant has reduced biofilm production. The relationship between motility and biofilm formation has been previously examined in connection with the $X$. fastidiosa diffusible signal factor (DSF) and the rpf gene cluster which encodes the DSF synthetase, RpfF, and the related two-component signaling proteins, RpfC/RpfG. DSF production is important for $X$. fastidiosa colonization within the insect vector and for disease development within the plant (Newman et al. 2004). Contrary to the pil $L_{2}$ mutant findings, mutations in the $r p f$ gene cluster that eliminate DSF production exhibit reduced biofilm formation and enhanced $X$. fastidiosa motility (Chatterjee et al. 2008b). Our results suggest that the relationship between biofilm formation and the Pil-Chp operon will require further exploration of intracellular signaling or gene regulation.

Our results indicate that the Pil-Chp operon plays a role in PD development. We found that inoculation by the $X$. fastidiosa pil $L_{2}$ mutant, which does not perform twitching motility and exhibits reduced biofilm formation, results in slower disease progression and severity. Dispersal of $X$. fastidiosa in the plant and disease development have been previously linked. DSF mutants of $X$. fastidios $a$, which exhibit reduced biofilm and greater motility, are hypervirulent in planta (Chatterjee et al. 2008b). The hypervirulent response is proposed to result from the increased movement of the pathogen within the grapevines. Paralleling this logic, we observed that the nonmotile pil $L_{2}$ mutant has reduced disease progression. However, grapevines infected with the pilL $L_{2}$ mutant do show symptoms, suggesting that motility is not the sole factor involved in PD. A relationship between biofilm formation and disease severity has also been reported. For instance, mutations in $\sigma$ factor 54 (RpoN) (da Silva et al. 2008) and global regulators algU and gacA (Shi et al. 2007, 2009) reduce both biofilm formation and PD progression. Therefore, one possible explanation for why the insertion mutation into the pilL gene does not eliminate disease is that the mutants still form biofilms.

It is likely that colonization of grapevines by $X$. fastidiosa and subsequent disease development is coordinated by a series of regulatory networks creating multiple virulent responses. As our knowledge of $X$. fastidiosa chemotaxis, pili production, and their regulation advances, the coordinated multisystem regulation of $X$. fastidios $a$ virulence will be elucidated. Future work will involve determining whether the Pil-Chp operon is a true chemotaxis system and, if so, its stimulus. Such knowledge will greatly enhance our understanding of the motility response and methods to block it. Understanding how such regulatory networks function and interact is central to determining how to approach the control of $X$. fastidiosa plant colonization and PD expression. 


\section{MATERIALS AND METHODS}

Bacterial strains.

$X$. fastidiosa Temecula isolate was cultured at $28^{\circ} \mathrm{C}$ on modified PW agar (Davis et al. 1981) in the absence of phenol red and with bovine serum albumin at $3.5 \mathrm{~g} /$ liter (Gibco product 15260; Invitrogen, Carlsbad, CA, U.S.A.). We previously generated a library of twitching motility mutants through transposon (EZ::TN Transposome; Epicentre Biotechnologies, Madison, WI, U.S.A.) mutagenesis of the $X$. fastidiosa Temecula isolate (Li et al. 2007). Mutants were cultured on modified PW containing kanamycin at $50 \mu \mathrm{g} / \mathrm{ml}$ (Sigma-Aldrich, St. Louis). Bacterial cultures were stored at $-80^{\circ} \mathrm{C}$ on modified PW broth containing 7\% final concentration DMSO (Sigma-Aldrich). E. coli was cultured on LB medium (Difco Laboratories, Detroit) amended with appropriate antibiotics (Sigma-Aldrich).

\section{Construction and screening}

of the $X$. fastidiosa pilL $L_{I}$ mutant.

Genomic DNA from the twitching-affected mutants was digested with $E c o$ RI, cloned into pUC18, transformed into $E$. coli, and selected on LB medium (Difco Laboratories) plus kanamycin at $50 \mu \mathrm{g} / \mathrm{ml}$ (Sigma-Aldrich). DNA sequences of disrupted genes were determined using transposon-specific primers KAN-2 FP-1 and KAN-2 RP-1 (Epicentre Biotechnologies), which amplify sequences outward from the transposon insertion. Approximately 800 to 1,000 nucleotides were sequenced for each mutant of interest at the Cornell University Life Sciences Core Laboratories Center (Ithaca, NY, U.S.A.). Genomic locations of Tn5 insertions were identified by BLAST search of the AEG $X$. fastidiosa Temecula genome database and compared with the SABIA $X$. fastidiosa genome database. Analyses of DNA were carried out with DNASTAR software (DNASTAR Inc, Madison, WI, U.S.A.).

Total genomic DNA was extracted from 5-ml cultures of $X$. fastidiosa Temecula using the Mo Bio Ultraclean Microbial DNA kit (Mo Bio Laboratories, Carlsbad, CA, U.S.A.) as described by the manufacturer. Southern blots were performed to verify single $T n 5$ insertions within each mutant. Analyses utilized the digoxigenin DNA labeling and detection kit (Boehringer Mannheim GmbH, Mannheim, Germany) with a Tn5 probe contained on the EZ-Tn Kan2 transposon, according to the manufacturer's instructions. Briefly, genomic DNA of the selected mutants was double digested with EcoRI and HindIII, denatured with $\mathrm{NaOH} / \mathrm{HCl}(0.4 \mathrm{~N} / 0.25 \mathrm{~N})$ solution, transferred, and fixed to the membrane. The fixed membrane was probed followed by hybridization and membrane development.

Mutants were screened for twitching motility on modified PW as described by Cursino and associates (2009). Bacterial colonies lacking a peripheral fringe, a morphological indicator of twitching motility, were tested at least three times to verify the twitching-defective phenotype. Subsequently, for isolates that did not readily exhibit a peripheral fringe, cells were spread sparsely onto either the agar surface or onto a sterilized sheet of cellophane overlaid on the agar surface and examined for twitching motility within 1 to 3 days. Cellophane provided a surface on which colonies with twitching cells exhibited a broader and more defined fringe than when examined on an agar surface only.

\section{Construction and screening \\ of the $X$. fastidiosa pilL $L_{2}$ mutant.}

The pill $L_{2}$ mutant was created by allelic exchange according to Chatterjee and associates (2008b). Briefly, a 5.6-kb region of $X$. fastidiosa genomic DNA including the pill gene was amplified with REDAccuTaq LA DNA polymerase (Sigma-Aldrich) with specific primers PilL .For and PilL $_{2}$.Rev (Table 2) and cloned into the BamHI site of pUC19 (Invitrogen) to obtain pLC1. Plasmid pLC1 was sequenced to confirm the presence of an intact pilL gene with primers PilL $_{2}$.For.seq and PilL ${ }_{2}$.Rev.seq. Then, pLC1 was mutagenized using in vitro transposition via EZ-Tn5-Kan-2 (Epicentre Biotechnologies) according to the manufacturer's instructions. The presence of a transposon insertion was detected by PCR and its location verified by sequencing. Plasmid pLC2 was selected as having a single-transposon insertion at the 968th codon of the cloned pilL gene. pLC2 was electroporated into $X$. fastidiosa, and transformants were selected on PW medium containing kanamycin at $50 \mu \mathrm{g} / \mathrm{ml}$. The disruption of the pilL locus in marker-exchange mutants was confirmed by sequencing and PCR with primers pil $L_{2}$.For and pilL $L_{2}$. Rev. A $0.56-\mathrm{kb}$ fragment from the wild-type and a $1.5-\mathrm{kb}$ fragment from the mutant were sequenced and compared with $X$. fastidios $a$ genomic sequences or Tn5 transposon sequences with vector pUC19. The pilL::kan-2 null mutant strain was designated pilL $L_{2}$.

Table 2. Primers used in this work

\begin{tabular}{|c|c|c|}
\hline Purpose & Primers & Sequence $\left(5^{\prime}\right.$ to $\left.3^{\prime}\right)$ \\
\hline \multirow[t]{4}{*}{ PilL $_{2}$} & PilL $_{2}$.For & ATGGATCCAGACTGC TGAATCGATCGGTC \\
\hline & $\operatorname{PilL}_{2} \cdot \operatorname{Rev}$ & ATGGATCCCAGCACACCCCAGTAATGCAAC \\
\hline & PilL $_{2}$.For.seq & TGCTGTAGTCGAGCCAGAAAAG \\
\hline & PilL $_{2} \cdot$ Rev.seq & CCTGTGTACGTGCTTTGAGAGT \\
\hline \multirow[t]{10}{*}{ RT-PCR ${ }^{\mathrm{a}}$} & PilG.For & ACCTTTTACACGCGAGGAGTT \\
\hline & Pill.Rev & GGGACAATCTGAACAACCTCA \\
\hline & Pill.For & TGAACGTGTGTTTTTGGTTGA \\
\hline & PilJ.Rev & ACACCTGCAAGTTAGCCACAT \\
\hline & PilJ.For & GATCAGCAGCCAACTTCAAAT \\
\hline & PilL.Rev & CAGGTAATCAGCGCAAGAAAG \\
\hline & PilL.For & GTCAACGTGCCTTTGAAATTG \\
\hline & ChpB.Rev & ATTACTGGTTCAAGGGCGATT \\
\hline & ChpB.For & GCTTATCGAGCTTGATGGACA \\
\hline & ChpC.Rev & CCAACTAACCAAGAAGGCACA \\
\hline \multirow[t]{2}{*}{ Pil-Chp promoter } & nCG1F & GGGGTACCTTATACGGCAATTGCCA \\
\hline & nCG16R & GGGTCTAGATGCCAATATCCTCATGC \\
\hline \multirow[t]{2}{*}{ pilL-chpB-chpC } & nCG26R & GGGCTCGAGTTAAATGTGGCCACAA \\
\hline & $\mathrm{nCG} 30 \mathrm{~F}$ & GGGTCTAGAATGAACGCACTTCGTG \\
\hline \multirow[t]{2}{*}{ pilL mutagenesis } & nCG34F & GCTGGGTAAAGCCTGATCTGGATGAAGCTTTGGGCCAG \\
\hline & nCG35R & CTTGGCCCAAAGCTTCATCCAGATCAGGCTTTACCCAGC \\
\hline \multirow[t]{2}{*}{$\operatorname{chpC}$ mutagenesis } & $\mathrm{nCG} 32 \mathrm{~F}$ & CGCTATTGCCTGATCTGGATACAATTGAAAATGCC \\
\hline & nCG33R & GGCATTTTCAATTGTATCCAGATCAGGCAATAGCG \\
\hline
\end{tabular}

\footnotetext{
${ }^{\text {a }}$ Reverse-transcription polymerase chain reaction.
} 
Construction of plasmids for complementation.

The Pil-Chp promoter was identified using transcriptional regulation information from the SABIA $X$. fastidios $a$ genome project website. The ribosome-binding site as well as several putative -35 and -10 boxes were identified upstream of pilG, the first gene in the operon. Vector pAX1Cm (Matsumoto et al. 2009) containing the Pil-Chp promoter was created by PCR amplification of $X$. fastidiosa genome bases $1,047,423$ to 1,047,578 using primers (Integrated DNA Technologies, Coralville, IA, U.S.A.) nCG1F (KpnI site engineered into primer) and nCG16R (pilG start site replaced with $\mathrm{XbaI}$ site) and HiFidelity polymerase (Qiagen, Valencia, CA, U.S.A.). The pilG start site is located at genome base $1,047,573$. The resulting plasmid, pCG1, was verified by DNA sequence analysis (Cornell Core Sequencing Facility). This promoter construct successfully expressed other $X$. fastidiosa genes (unpublished data).

In order to clone pilL-chpB-chpC into plasmid pCG1, existing $X b a \mathrm{I}$ sites in both the pilL and $\operatorname{chpC}$ genes needed to be removed. The pilL-chpB-chpC genes were amplified from genomic DNA using HiFidelity polymerase (Qiagen) and primers (Sigma-Aldrich) nCG26R and nCG30F. The product was then cloned into pGEM T-Easy (Promega Corp., Madison, WI, U.S.A.). The $X b a \mathrm{I}$ site in the pilL gene was changed using primers nCG34F and nCG35R (Sigma-Aldrich) with the QuikChange site-directed mutagenesis kit approach (Stratagene, La Jolla, CA, U.S.A.) to create a silent mutation. The XbaI site in $\operatorname{ch} p C$ was similarly modified, except with primers nCG32F and nCG33R. The modified pilL-chpB-chpC genes were amplified by PCR using HiFidelity polymerase (Qiagen) and nCG26R and nCG30F primers (Sigma-Aldrich) and cloned into plasmid pCG1. Plasmid pCG1 containing pilL-chpB-chpC was named pCG2. The construct was verified by DNA sequence analysis of the entire pilL-chpB-chpC coding region (Cornell Core Sequencing Facility). Plasmid pCG2 was electroporated into $X$. fastidiosa strain pil $L_{2}$ and plated on PW agar supplemented with kanamycin at $50 \mu \mathrm{g} / \mathrm{ml}$ and chloramphenicol at $10 \mu \mathrm{g} / \mathrm{ml}$.

\section{Assay for twitching motility.}

Colony fringe phenotypes were confirmed on cellophane overlaid on agar plates as described above. The pilL $L_{1}$ and pil $L_{2}$ mutants were also examined microscopically in fabricated microfluidic chambers (see below) and for movement across the agar surface using time-lapse imaging as described below. Temporal and spatial observations of the colony fringes of wild-type and pilL $L_{1}$ and pilL $L_{2}$ mutants were performed with an inverted IMT-2 Olympus microscope using a 40× phase-contrast objective. Time-lapse images were recorded with either a SPOT-RT digital camera (Diagnostic Instruments, Inc., Sterling Heights, MI, U.S.A.) or a CoolSNAP cf digital camera (Photometrics, Tucson, AZ, U.S.A.), both controlled by MetaMorph imaging software (Universal Imaging, Downington, PA, U.S.A.).

\section{Cell motility in microfluidic chambers.}

The speed at which wild-type and mutant cells migrated against the flow of media was assessed in microfluidic devices as previously described (De La Fuente et al. 2007a). Flow of PD2 medium, controlled by a syringe pump, was maintained at $1 \times 10^{4} \mu \mathrm{m} \mathrm{m^{-1 }}$. Cells attached to the glass surface of the microfluidic channels were observed microscopically using time-lapse image recordings every $30 \mathrm{~s}$ as previously reported (De La Fuente et al. 2007b). In all, 25 to 30 individual cells were tracked for the wild-type and pil $L_{2}$ from three independent experiments. Data were analyzed with the Kruskal-Wallis test and means were separated by the Kruskal-Wallis all pairwise comparison test $(P=0.05)$.

\section{Protein identity and domains.}

The pilL, $\operatorname{chpB}$, and $\operatorname{chpC}$ genes and protein products were characterized using a combination of BLAST searches of GenBank (Altschul et al. 1997) together with PFAM (Bateman et al. 2002) and SMART (Letunic et al. 2002) programs. The ProtParam tool on the ExPASyserver was used to calculate molecular weights (Gasteiger et al. 2005). The Conserved Domain Database was used for conserved domains identification (Marchler-Bauer et al. 2007).

\section{RT-PCR analysis.}

$X$. fastidiosa total RNA was isolated with Trizol reagent (Invitrogen), and residual DNA was removed by treatment with 1 U of RQ1 RNase-free DNase I (Promega Corp.) and $4 \mathrm{U}$ of the RNase inhibitor RNaseOUT (Invitrogen) per microgram of RNA. RNA integrity was checked with the Experion Automated Electrophoresis System (Bio-Rad, Hercules, CA, U.S.A.), and the lack of residual DNA was checked by PCR. Quantification was performed on a NanoDrop ND-1000 spectrophotometer according to the manufacturer's instructions (NanoDrop, Wilmington, DE, U.S.A.). All oligonucleotide primers used for RT-PCR were synthesized by Integrated DNA Technologies and are described in Table 2. RT-PCR was carried out with $5 \mu \mathrm{g}$ of $X$. fastidiosa total RNA primed with $500 \mathrm{ng}$ of random hexamers using the SuperScript III one-step RT-PCR system (Invitrogen). Each amplicon $(5 \mu \mathrm{l})$ was electrophoresed on a $1.2 \%$ agarose gel.

\section{Growth analysis.}

To assess the influence of the transposon insertion into the pilL gene on $X$. fastidiosa growth rate, growth curves for wildtype, the pilL $L_{2}$ mutant, and the complemented mutant were compared. The growth curves were constructed from data obtained over a 10-day period and performed as described by Galvani and associates (2007). The experiment was repeated three independent times.

\section{Transmission electron microscopy.}

Mutants were also assessed for the presence of type I and type IV pili. Cells were obtained from 2- to 3-day-old cultures spread over cellophane overlaid on PW agar. Cells were scraped from the cellophane and mixed with distilled water, deposited on Formvar-coated grids, dried, and subsequently stained with either phosphotungstic acid or uranyl acetate, and examined with a JEOL S-100 transmission electron microscope.

\section{Biofilm formation assay.}

Biofilm formation was analyzed as described by $\mathrm{Li}$ and associates (2007). Briefly, wild-type, pilL $L_{2}$ mutant, and the complemented mutant cells from 7-day-old cultures grown on PW agar plates were transferred to and grown in 100-ml glass Erlenmeyer flasks containing $50 \mathrm{ml}$ of PD2 broth. The flasks were incubated at $28^{\circ} \mathrm{C}$ with agitation $(195 \mathrm{rpm})$ for 10 days, after which biofilm formation was assessed.

Biofilm formation quantitation was assessed in 96-well polystyrene culture plates per established procedures except for the following (Zaini et al. 2009). Bacterial cultures were maintained for 7 instead of 5 days at $28^{\circ} \mathrm{C}$, with agitation at $200 \mathrm{rpm}$. In total, 60 samples for each bacterial strain were used.

\section{$X$. fastidiosa pathogenicity assay.}

The $X$. fastidiosa pathogenicity assay was performed according to Roper and associates (2007) with modifications. Vitis vinifera L. 'Cabernet Sauvignon' grapevines grown in the greenhouse for 2 months were inoculated by needle puncture. Ten plants per treatment were inoculated at four basal internodes of 
each branch with $20-\mu$ d drops containing a bacterial cell suspension at approximately $1 \times 10^{9} \mathrm{CFU} / \mathrm{ml}$ in SCP buffer (wild type, pil $_{2}$ mutant, or buffer only) (Hopkins 1984). At 4 weeks after inoculation and every 4 weeks until week 20, the plants were rated for PD symptoms on a scale of 0 to 5 (Guilhabert and Kirkpatrick 2005), where $0=$ no PD symptoms, $1=$ one or two leaves just beginning to show marginal necrosis, $2=$ two to three leaves with significant marginal necrosis, $3=$ one half or more of the leaves showing marginal necrosis and a few matchsticks (attached petioles with abscised leaf blade), $4=$ all of the leaves showing heavy scorching and numerous matchsticks, and $5=\mathrm{a}$ dead vine. The average $(n=10)$ of ratings from each treatment and control were submitted to one-way analysis of variance with repeated measures. The paired $t$ test procedure was performed as a post-hoc test using Bonferroni correction and a 95\% confidence level.

\section{ACKNOWLEDGMENTS}

This work was supported, in part, from grants provided through the United States Department of Agriculture Cooperative State Research, Education, and Extension Service administered through the University of California Pierce's Disease Research Grants Program to T. J. Burr, H. C. Hoch, and P. Mowery and by funding to H. C. Hoch from the Nanobiotechnology Center, an STC program of the National Science Foundation, under agreement no. ECS-9876771. We thank M. J. Welser, C. L. Reid, and A. Schenk for their technical assistance.

\section{LITERATURE CITED}

Alexander, R. P., and Zhulin, I. B. 2007. Evolutionary genomics reveals conserved structural determinants of signaling and adaptation in microbial chemoreceptors. Proc. Natl. Acad. Sci. U.S.A. 104:28852890.

Almeida, R. P. P., Blua, M. J., Lopes, J. R. S., and Purcell, A. H. 2005. Transmission of Xylella fastidiosa: Applying fundamental knowledge to generate disease management strategies. Annu. Entomol. Soc. Am. 98:775-786.

Altschul, S. F., Madden, T. L., Schaffer, A. A., Zhang, J., Zhag, Z., Miller, W., and Lipman, D. J. 1997. Gapped BLAST and PSI-BLAST: A new generation of protein database search programs. Nucleic Acids Res. 25:3389-3402.

Bateman, A., Birney, E., Cerruti, L., Durbin, R., Etwiller, L., Eddy, S. R., Griffiths-Jones, S., Howe, K. L., Marshall, M., and Sonnhammer, E. L. 2002. The Pfam protein families database. Nucleic Acids Res. 30:276280.

Bhaya, D., Takahashi, A., and Grossman, A. R. 2001. Light regulation of type IV pilus-dependent motility by chemosensor-like elements in Synechocystis PCC6803. Proc. Natl. Acad. Sci. U.S.A. 98:75407545 .

Chatterjee, S., Almeida, R. P. P., and Lindow, S. 2008a. Living in two worlds: The plant and insect lifestyles of Xylella fastidiosa. Annu. Rev. Phytopathol. 46:243-271.

Chatterjee, S., Newman, K. L., and Lindow, S. E. 2008b. Cell-to-cell signaling in Xylella fastidiosa suppresses movement and xylem vessel colonization in grape. Mol. Plant-Microbe Interact. 21:1309-1315.

Cursino, L., Li, Y., Zaini, P. A., De La Fuente, L., Hoch, H. C., and Burr, T. J. 2009. Twitching motility and biofilm formation are associated with tonB1 in Xylella fastidiosa. FEMS (Fed. Eur. Microbiol. Soc.) Microbiol. Lett. 299:193-199.

Darzins, A. 1993. The pilG gene product, required for Pseudomonas aeruginosa pilus production and twitching motility, is homologous to the enteric, single-domain response regulator CheY. J. Bacteriol. 175:5934-5944.

Darzins, A. 1994. Characterization of a Pseudomonas aeruginosa gene cluster involved in pilus biosynthesis and twitching motility: Sequence similarity to the chemotaxis proteins of enterics and the gliding bacterium Myxococccus xanthus. Mol. Microbiol. 11:137-153.

da Silva Neto, J. F., Koide, T., Abe, C. M., Gomes, S. L., and Marques, M. V. 2008. Role of sigma54 in the regulation of genes involved in type I and type IV pili biogenesis in Xylella fastidiosa. Arch Microbiol. 189:249-261

Davis, M. J., French, W. J., and Schaad, N. W. 1981. Axenic culture of the bacteria associated with phony disease of peach and plum leaf scald. Curr. Microbiol. 6:309-314.
De La Fuente, L., Burr, T. J., and Hoch, H. C. 2007a. Mutations in type I and type IV pilus biosynthetic genes affect twitching motility rates in Xylella fastidiosa. J. Bacteriol. 189:7507-7510.

De La Fuente, L., Montanes, E., Meng, Y., Li, Y., Burr, T. J., Hoch, H. C., and Wu, M. 2007b. Assessing adhesion forces of type I and type IV pili of Xylella fastidiosa using a microfluidic flow chamber. Appl. Environ. Microbiol. 73:2690-2696.

DeLange, P. A., Collins, T. L., Pierce, G. E., and Robinson, J. B. 2007. PilJ localizes to cell poles and is required for type IV pilus extension in Pseudomonas aeruginosa. Curr. Microbiol. 55:389-395.

Falke, J. J., and Hazelbauer, G. L. 2001. Transmembrane signaling in bacterial chemoreceptors. Trends Biochem. Sci. 26:257-265.

Ferandez, A., Hawkins, A. C., Summerfield, D. T., and Harwood, C. S. 2002. Cluster II che genes from Pseudomonas aeruginosa are required for an optimal chemotactic response. J. Bacteriol. 184:4374-4383.

Fulcher, N. B., Holliday, P. M., Klem, E., Cann, M. J., and Wolfgang, M. C. 2010. The Pseudomonas aeruginosa Chp chemosensory system regulates intracellular cAMP levels by modulatine adenylate cyclase activity. Mol. Microbiol. 76:889-904.

Galvani, C. D., Li, Y., Burr, T. J., and Hoch, H. C. 2007. Twitching motility among pathogenic Xylella fastidiosa isolates and the influence of bovine serum albumin on twitching-dependent colony fringe morphology. FEMS (Fed. Eur. Microbiol. Soc.) Microbiol. Lett. 268:202-208.

Gasteiger, E., Hoogland, C., Gattiker, A., Duvaud, S., Wilkins, M. R., Appel, R. D., and Bairoch, A. 2005. Protein identification and analysis tools on the ExPASy server. Pages 571-607 in: The Proteomics Protocols Handbook. J. M. Walker, ed. Humana Press, Totowa, NJ, U.S.A.

Guilhabert, M. R., and Kirkpatrick, B. C. 2005. Identification of Xylella fastidiosa avirulence genes: Hemagglutinin adhesins contribute to $X$ fastidiosa biofilm maturation and colonization and attenuate virulence. Mol. Plant-Microbe Interact. 18:856-868.

Hamer, R., Chen, P. Y., Armitage, J. P., Reinert, G., and Deane, C. M. 2010. Deciphering chemotaxis pathways using cross species comparisons. BMC Syst. Biol. 4:3.

Hazelbauer, G. L., Falke, J. J., and Parkinson, J. S. 2008. Bacterial chemoreceptors: High-performance signaling in networked arrays. Trends Biochem. Sci. 33:9-19.

Hopkins D. L. 1984. Variability of virulence in grapevine among isolates of the Pierce's disease bacterium. Phytopathology 74:1395-1398.

Kirby, J. R. 2009. Chemotaxis-like regulatory systems: Unique roles in diverse bacteria. Annu. Rev. Microbiol. 63:45-59.

Krueger, J. K., Stock, J., and Schutt, C. E. 1992. Evidence that the methylesterase of bacterial chemotaxis may be a serine hydrolase. Biochim. Biophys. Acta 1119:332-326.

Letunic, I., Goodstadt, L., Dickens, N. J., Doerks, T., Schultz, J., Mott, R. Ciccarelli, F., Copley, R. R., Ponting, C. P., and Bork, P. 2002. Recent improvements to the SMART domain-based sequence annotation resource. Nucleic Acids Res. 30:242-244.

Li, Y., Hao, G., Galvani, C. D., Meng, Y., De La Fuente, L., Hoch, H. C., and Burr, T. J. 2007. Type I and type IV pili of Xylella fastidiosa affect twitching motility, biofilm formation and cell-cell aggregation. Microbiology 153:719-726.

Marchler-Bauer, A., Anderson, J. B., Derbyshire, M. K., DeWeese-Scott, C., Gonzales, N. R., Gwadz, M., Hao, L., He, S., Hurwitz, D. I., Jackson, J. D., Ke, Z., Krylov, D., Lanczycki, C. J., Liebert, C. A., Liu, C., Lu, F., Lu, S., Marchler, G. H., Mullokandov, M., Song, J. S., Thanki, N., Yamashita, R. A., Yin, J. J., Zhang, D., and Bryant, S.H. 2007. CDD: A conserved domain database for interactive domain family analysis. $\mathrm{Nu}-$ cleic Acids Res. 35:237-240.

Matsumoto, A., Young, G. M., and Igo, M. M. 2009. Chromosome-based genetic complementation system for Xylella fastidiosa. Appl. Environ. Microbiol. 75:1679-1687.

Mattick, J. S. 2002. Type IV pili and twitching motility. Annu. Rev. Microbiol. 56:289-314.

Meng, Y., Galvani, C. D., Hao, G., Turner, J. N., Burr, T. J., and Hoch, H. C. 2005. Upstream migration of Xylella fastidiosa via pilus-driven twitching motility. J. Bacteriol. 187:5560-5567.

Newman, K. L., Almeida, R. P. P., Purcell, A. H., and Lindow, S. E. 2004 Cell-cell signaling controls Xylella fastidiosa interactions with both insects and plants. Proc. Natl. Acad. Sci. U.S.A. 101:1737-1742

Purcell, A. H., and Hopkins, D. L. 1996. Fastidious xylem-limited bacterial plant pathogens. Annu. Rev. Phytopathol. 34:131-151.

Roper, M. C., Greve, L. C., Warren, J. G., Labavitch, J. M., and Kirkpatrick, B. C. 2007. Xylella fastidiosa requires polygalacturonase for colonization and pathogenicity in Vitis vinifera grapevines. Mol. Plant-Microbe Interact. 50:411-419.

Sanders, D. A., Gillece-Castro, B. L., Stock, A. M., Burlingame, A. L., and Koshland, D.E., Jr. 1989. Identification of the site of phosphorylation of the chemotaxis response regulator protein, CheY. J. Biol. Chem. 264:21770-21778. 
Shi, X. Y., Dumenyo, C. K., Hernandez-Martinez, R., Azad, H., and Cooksey, D. A. 2007. Characterization of regulatory pathways in $X y$ lella fastidiosa: Genes and phenotypes controlled by algU. Appl. Environ. Microbiol. 73:6748-6756.

Shi, X. Y., Dumenyo, C. K., Hernandez-Martinez, R., Azad, H., and Cooksey, D. A. 2009. Characterization of regulatory pathways in $X y$ lella fastidiosa: Genes and phenotypes controlled by gacA. Appl. Environ. Microbiol. 75:2275-2283.

West, A. H., Martinez-Hackert, E., and Stock, A. M. 1995. Crystal structure of the catalytic domain of the chemotaxis receptor methylesterase, CheB. J. Mol. Biol. 250:276-290.

Whitchurch, C. B., Leech, A. J., Young, M. D., Kennedy, D., Sargent, J. L., Bertrand, J. J., Semmler, A. B., Mellick, A. S., Martin, P. R., Alm, R. A., Hobbs, M., Beatson, S. A., Huang, B., Nguyen, L., Commolli, J. C., Engel, J. N., Darzins, A., and Mattick, J. S. 2004. Characterization of a complex chemosensory signal transduction system which controls twitching motility in Pseudomonas aeruginosa. Mol. Microbiol. 52:873-893.

Winther-Larsen, H. C., and Koomey, M. 2002. Transcriptional, chemosen- sory and cell-contact-dependent regulation of type IV pilus expression. Curr. Opin. Microbiol. 5:173-178.

Wuichet, K., Alexander, R. P., and Zhulin, I. B. 2007. Comparative genomic and protein sequence analyses of a complex system controlling bacterial chemotaxis. Methods Enzymol. 422:1-31.

Zaini, P. A., De La Fuente, L., Hoch, H. C., and Burr, T. J. 2009. Grapevine xylem sap enhances biofilm development by Xylella fastidiosa. FEMS (Fed. Eur. Microbiol. Soc.) Microbiol. Lett. 295:129-134.

Zusman, D. R., Scott, A. E., Yang, Z., and Kirby, J. R. 2007. Chemosensory motility and development in Myxococcus xanthus. Nat. Rev. Microbiol. 5:862-872.

AUTHOR-RECOMMENDED INTERNET RESOURCES

Agronomical and Environmental Genomes (AEG) Xylella fastidiosa database: aeg.lbi.ic.unicamp.br/world/xfpd/

System for Automated Bacterial Integrated Annotation (SABIA) Xylella fastidiosa genome project: xylella.lncc.br

The name of an enzyme used in this research has been corrected in the online article on May 31, 2012. 